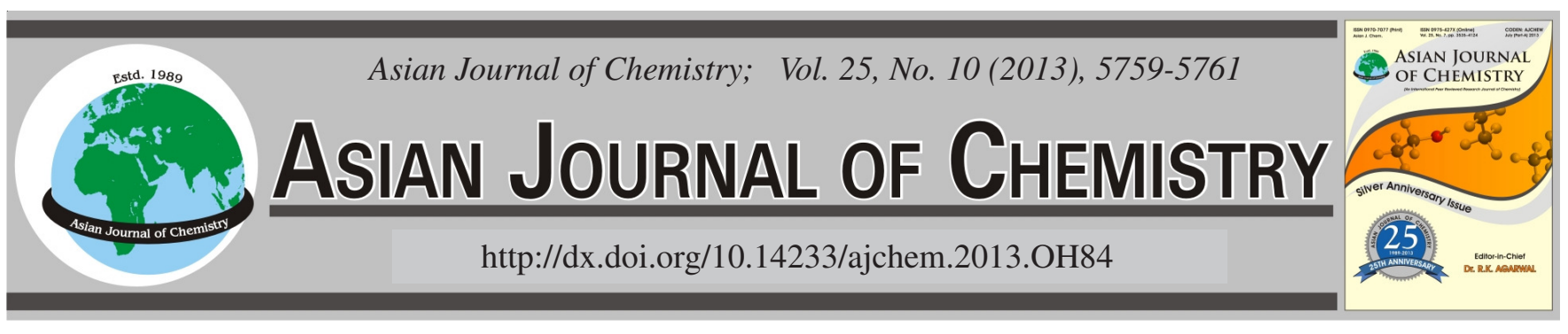

\title{
Phosphorus Removal from Eutrophic Waters with a Novel Lanthanum-Modified Diatomite $\dagger$
}

\author{
Fazhi XIE ${ }^{1, *}$, Chunnian Da ${ }^{2}$, Fenguun Zhang ${ }^{1}$, Jun Zhang ${ }^{1}$, XuAn Han $^{1}$, Yejun Ge ${ }^{1}$ and Guolian Li ${ }^{3}$
}

\begin{abstract}
${ }^{1}$ School of Materials Science and Chemical Engineering, Anhui University of Architecture, Hefei 230022, P.R. China
${ }^{2}$ Department of Biological and Environmental Engineering, Hefei University; Hefei 230022, P.R. China

${ }^{3}$ School of Environment and Energy Engineering, Anhui University of Architecture, Hefei 230022, P.R. China
\end{abstract}

*Corresponding author: E-mail: fzhxie@gmail.com

A novel phosphorus adsorbent, lanthanum-modified diatomite was prepared by a simple coating method and exhibited high adsorption and removal efficiency for phosphorus in aqueous solutions. After being modified by lanthanum hydroxide, the surface area of diatomite increased 85-fold and the pore volume increased 390 times. These characteristics are responsible for the increased phosphorus adsorption efficiency. Adsorption behaviour for phosphorus depended mainly on the $\mathrm{pH}$ of solution, contact time, initial $\mathrm{P}$ concentration and co-exist anion ions. The as-prepared sorbent can be used to remove phosphorus from eutrophic lake water efficiently.

Key Words: Phosphorus, Lanthanum-modified diatomite, Remove, Adsorption, Lake.

\section{INTRODUCTION}

Phosphorus, needed for DNA, RNA and energy transfer is the key limiting nutrients in most lake systems ${ }^{1,2}$. Large phosphorus inputs to lakes result in eutrophication and limit the utilization of lake water severely, which are the most extrusive problem of lake in China ${ }^{3}$. Though the external phosphorus input was controlled gradually, the internal phosphorus which releases from lake sediments is becoming the most important source of phosphorus in lake systems ${ }^{4,5}$. The removal of phosphorus by adsorption from water can be an effective method for its recovery and control of eutrophication in lakes and similar confined water bodies ${ }^{6}$. Adsorbents used in the literature are composite adsorbents such as iron oxide ${ }^{7,8}$, ferrihydrite-modified diatomite ${ }^{6}$, polymer gel ${ }^{9}, \mathrm{TiO}_{2}{ }^{10}$, steel slags ${ }^{11}$ modified $\mathrm{SiO}_{2}{ }^{12}$, $\mathrm{LDH}^{13}$ and $\mathrm{Fe}-\mathrm{Mn}$ binary oxide ${ }^{14}$ have been investigated for the removal of phosphorus form an aquatic environment. Although a few studies are available on the use of a support modified with lanthanum as an adsorbent to remove phosphorus from water ${ }^{15-17}$, there has been little information on the adsorption of phosphorus by a diatomite modified with lanthanum hydroxide. The objectives of this work are: (1) to characterize the lanthanum modified diatomite by scanning electron microscope (SEM), BET and elemental analysis in detail; (2) to investigate the adsorption of phosphorus on modified diatomite under various common conditions and (3) to study the phosphorus removal efficiency from eutrophic lake water samples by lanthanum modified diatomite.

\section{EXPERIMENTAL}

The surface morphology measurements were carried out with a JEOL JSM-6700F scanning electron microscope (SEM). Surface areas were obtained by ASAP2020 M+C system (Micromeritics, USA). The $\mathrm{pH}$ measurements were conducted by a PHS-3C pH-meter (Dapu instrumentation Corp. Ltd., Shanghai, China). Diatomite was obtained from Changbai Diatomite Co. Ltd., Jilin, China. $\mathrm{LaCl}_{3} \cdot 7 \mathrm{H}_{2} \mathrm{O}$ and $\mathrm{KH}_{2} \mathrm{PO}_{4}$ (Sinopharm Chemical Reagent Co. Ltd.) are analytical-grade reagents and were used without further purification.

Preparation of lanthanum-modified diatomite: In a typical synthesis, $15 \mathrm{~g}$ of diatomite samples were immersed in $100 \mathrm{~mL}$ of $6 \mathrm{M}$ sodium hydroxide. The reaction temperature was maintained at $85^{\circ} \mathrm{C}$ for $2 \mathrm{~h}$ to partially dissolve $\mathrm{Si}^{6}$. The mixture was then placed in $100 \mathrm{~mL}$ of $0.2 \mathrm{M} \mathrm{LaCl}_{3}$ under continuous magnetic stirring at room temperature for $24 \mathrm{~h}$. The mixture was centrifuged to remove the supernatant. The solid obtained through centrifugation was washed until no chloride ion could be detected by an aqueous $\mathrm{AgNO}_{3}$ solution and then dried in an oven at $50{ }^{\circ} \mathrm{C}$, desiccated and stored in polyethylene bottle for future use. The amount of lanthanum hydroxides deposited on the diatomite was determined by dissolving the modified diatomite in $6 \mathrm{M} \mathrm{HCl}$ at $40^{\circ} \mathrm{C}$. Lanthanum ions were determined by the atomic absorption spectroscopy.

Sorption behaviour: $80 \mathrm{mg}$ of lanthanum-modified diatomite was equilibrated with a suitable amount of phosphorus

$\lceil$ Presented to the 6th China-Korea International Conference on Multi-functional Materials and Application, 22-24 November 2012, Daejeon, Korea 
solution which the $\mathrm{pH}$ was adjusted to desired value with dilute $\mathrm{NaOH}$ and $\mathrm{HCl}$ in a glass stoppered bottle $(100 \mathrm{~mL})$ at $25^{\circ} \mathrm{C}$ under magnetic stirring for a fixed period of time. After recovering the sorbent by centrifugation, the supernatants were analyzed by molybdenum blue method to determine the remaining concentrations of phosphorus in the water samples and the amount of phosphorus adsorbed was calculated using eq. (1).

$$
\mathrm{Q}_{\mathrm{eq}}=\frac{\mathrm{V}\left(\mathrm{C}_{0}-\mathrm{C}_{\mathrm{eq}}\right)}{\mathrm{m}}
$$

Removal of phosphorus from eutrophic lake water: Sorption of phosphorus in Yihai lake water by the lanthanummodified diatomite was investigated. The lake water samples were first filtered with cellulose acetate filters $(0.45 \mu \mathrm{m})$ and then spiked with phosphorus to make up two concentrations of phosphorus solution in lake water, viz. $10 \mathrm{mg} \mathrm{P} / \mathrm{L}$ and $5 \mathrm{mg}$ $\mathrm{P} / \mathrm{L}$, which represents typical concentration of phosphorus in different source of lake water polluted by domestic wastewaters.

\section{RESULTS AND DISCUSSION}

Lanthanum-modified diatomite: The physical parameters of raw diatomite and lanthanum-modified diatomite, such as the BET surface area, total pore volume, average pore diameter and lanthanum content were summarized in Table- 1 . The BET surface area of lanthanum-modified diatomite is $52.60 \mathrm{~m}^{2} / \mathrm{g}$, which is 82 -fold greater than that of raw diatomite. Fig. 1 shows the SEM of raw diatomite and lanthanum modified diatomite. Many pores can be seen on the surface of diatomite (Fig. 1a). The SEM micrograph of lanthanum modified diatomite reveals that raw diatomite frustules are surface modified and the original geometry of the pores is destroyed by the $\mathrm{NaOH}$ treatment (Fig. 1b). Initially, colloidal-size lanthanum hydroxide is in situ deposited into the macro-pores and larger mesopores of diatomite. After being fully deposited into the pores of diatomite, extra lanthanum hydroxide aggregates on the surface of diatomite particles. The porous structure can still be observed (Fig. 1b), which is beneficial for the phosphorus adsorption.

TABLE-1

\section{PHYSICOCHEMICAL CHARACTERISTIC OF SORBENTS}

\begin{tabular}{lcc}
\hline Property & Raw diatomite & $\begin{array}{c}\text { Lanthanum- } \\
\text { modified diatomite }\end{array}$ \\
\hline BET surface area $\left(\mathrm{m}^{2} / \mathrm{g}\right)$ & 0.64 & 52.60 \\
Total pore volume $\left(\mathrm{cm}^{3} / \mathrm{g}\right)$ & 0.00079 & 0.31 \\
Average pore diameter $(\mathrm{nm})$ & 49.5 & 23.8 \\
Lanthanum content $(\mathrm{mg} / \mathrm{g})$ & - & 126.05 \\
\hline
\end{tabular}
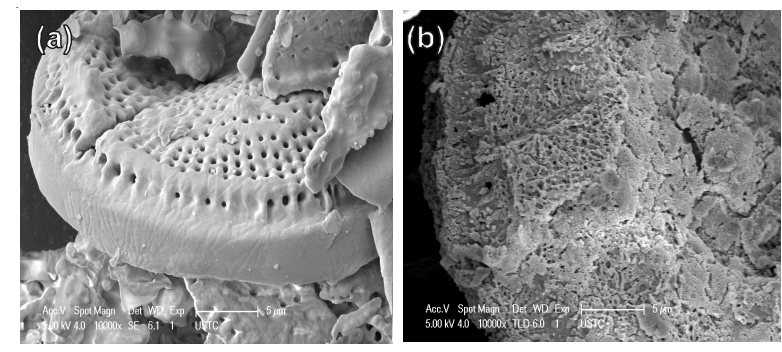

Fig. 1. SEM of raw diatomite (a) and lanthanum modified diatomite (b)

Effect of pH: The anion exchange capacity is strongly governed by the $\mathrm{pH}$ of the solution and by the surface chemistry of the solids. The total amount of phosphorus adsorbed by the lanthanum-modified diatomite under different $\mathrm{pH}$ values is shown in Fig. 2. The sorption capacity sharply increases with increasing $\mathrm{pH}$ from 2 and 4 and then tends to approach a maximum value at $\mathrm{pH} 5.0$, which is maintained until $\mathrm{pH} 7.0$ where after it decreases with further increases in $\mathrm{pH}$. In subsequent phosphorus sorption studies, the $\mathrm{pH}$ of the solutions was adjusted to 5.0. Species of phosphate present in lake water include $\mathrm{H}_{3} \mathrm{PO}_{4}, \mathrm{H}_{2} \mathrm{PO}_{4}{ }^{-}, \mathrm{HPO}_{4}{ }^{2-}$ and $\mathrm{PO}_{4}{ }^{3-}$ and their relative amounts depend on the $\mathrm{pH}$ of the medium. At $\mathrm{pH}>7$, the predominant species is $\mathrm{HPO}_{4}{ }^{2-}$, while at $\mathrm{pH}>4$, the predominant phosphate species is $\mathrm{H}_{2} \mathrm{PO}_{4}^{-}$, which should have a higher affinity than $\mathrm{HPO}_{4}^{2-}$ for the sorption center.

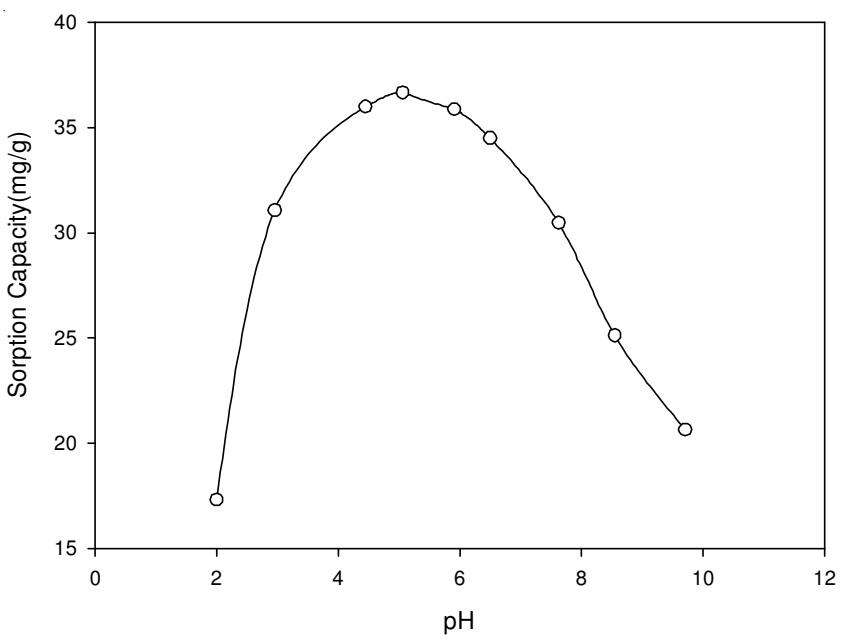

Fig. 2. Effect of $\mathrm{pH}$ on phosphorus adsorption

Effect of initial concentration of phosphorus: The effect of initial $\mathrm{P}$ concentration in the range of 5 to $50 \mathrm{mg} / \mathrm{L}$ on adsorption is shown in Fig. 3. The amount of phosphorus in the solid phase with lower initial concentration of phosphorus was smaller than the amount when higher concentrations were used. It is seen that the adsorption of phosphorus was dependent on the concentration of phosphorus in water samples. The decrease in the initial concentration increased the amount of phosphorus removed. While the percentage phosphorus removal was found to be $98.21 \%$ for $5 \mathrm{mg} / \mathrm{L}$ of initial concentration, this value was $56.25 \%$ for that of $50 \mathrm{mg} / \mathrm{L}$.

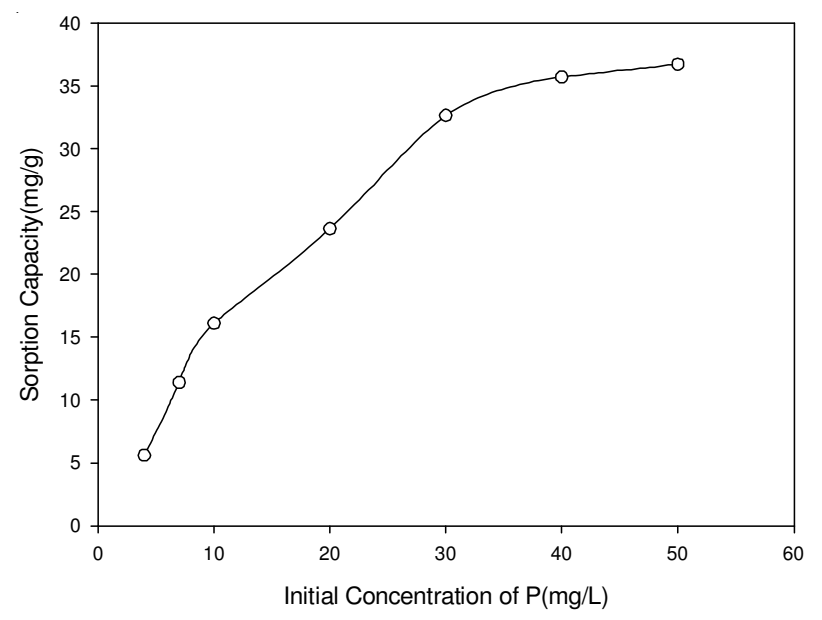

Fig. 3. Effect of initial concentration of phosphorus 
Effect of contact time: The effect of contact time on the amount of phosphorus adsorbed was investigated (Fig. 4). The amount of phosphorus adsorbed increased with the increase of contact time and reached equilibrium after $100 \mathrm{~min}$. The equilibrium time is independent of initial phosphorus concentration. But in the first $60 \mathrm{~min}$, the initial rate of adsorption was greater for higher initial phosphorus concentration. The diffusion of phosphate anion ion through solution to the surface of lanthanum-modified diatomite is affected by the phosphorus concentration. An increase of phosphorus concentration accelerates the diffusion of phosphate anion ion from the solution onto modified diatomite due to the increase in driving force of the concentration gradients.

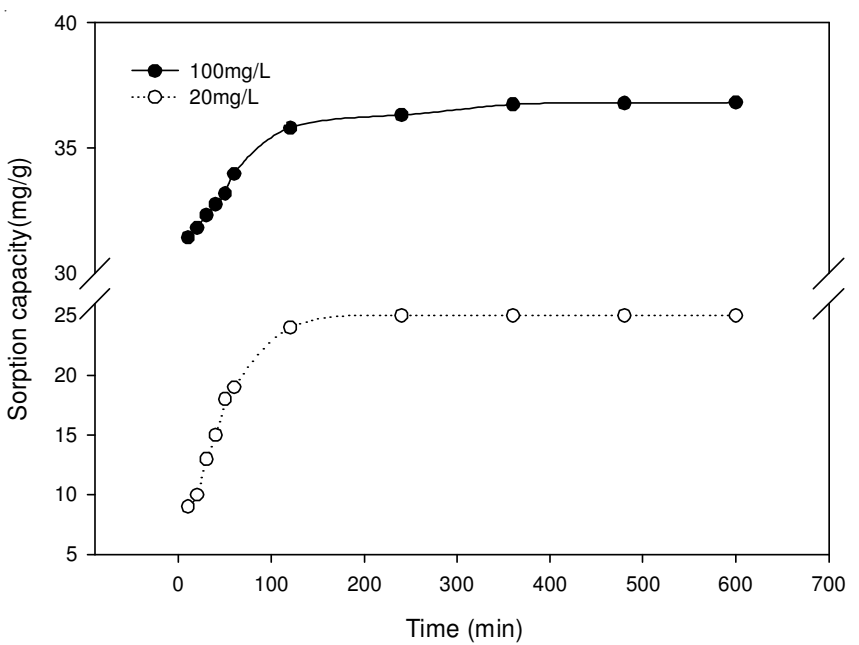

Fig. 4. Effect of contact time

Effect of anions on phosphorus sorption: Anionic species such as chloride, sulphate, oxalate, citrate, acetate, carbonate, nitrate ions are commonly found in lake water and may interfere with the phosphorus sorption process by competing for the sorption sites. To assess the effect of other anions on the sorption efficiency, a $5 \mathrm{mg} / \mathrm{L}$ phosphorus solution containing various amounts of other anion ions was used. The tolerance limits of the coexisting ions were defined as the maximum concentration of the foreign substances which could cause an approximately $\pm 5 \%$ relative error in the sorption capacity determination. The tolerance limit was found to be $1500 \mathrm{mg} / \mathrm{L}$ for oxalate and citrate, $2500 \mathrm{mg} / \mathrm{L}$ for acetate, chloride and nitrate, $500 \mathrm{mg} / \mathrm{L}$ for sulphate and $100 \mathrm{mg} / \mathrm{L}$ for carbonate. The results revealed that the lanthanum-modified diatomite is very efficient in removing phosphorus from water samples.

Eutrophic lake water phosphorus removal: The effect of dose of lanthanum-modified diatomite on the amount of phosphorus removal efficiency was studied in spiked lake water (Fig. 5). The equilibrium value of amount adsorbed was observed to decrease with increase in dose. The percentage removal of phosphorus increased with the increase in dose of adsorbent until a plateau is reached. This may be due to the increase in availability of surface active sites resulting from the increased dose of the adsorbent. A lanthanum-modified diatomite dose of $100 \mathrm{mg} / \mathrm{L}$ affords a phosphorus removal efficiency of $91 \%$ and $84 \%$ for $5 \mathrm{mg} / \mathrm{L}$ and $10 \mathrm{mg} / \mathrm{L}$ phosphorus respectively. When the adsorbent dose exceeds $140 \mathrm{mg} / \mathrm{L}$, phosphorus removal efficiency is consistently greater than $93 \%$.

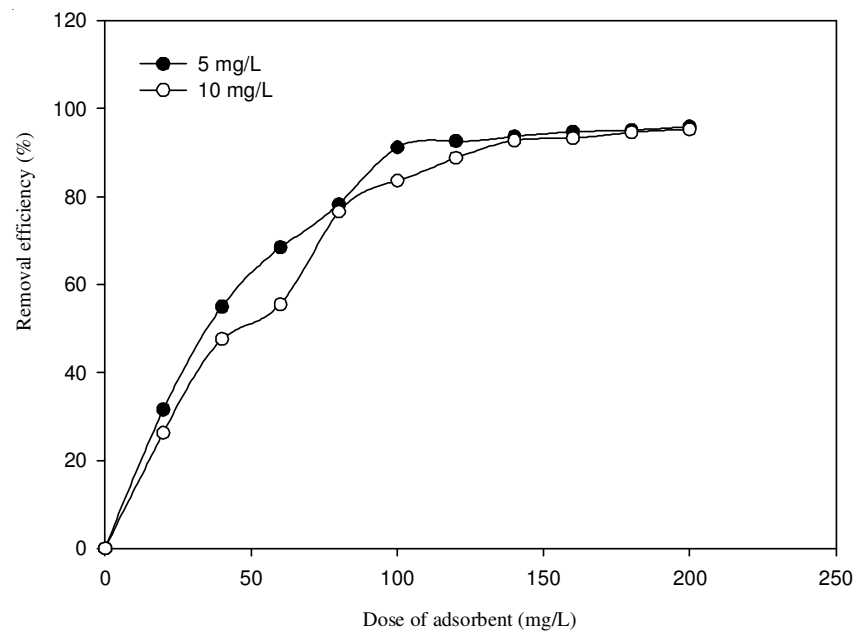

Fig. 5. Effects of lanthanum-modified diatomite dose on removal efficiency of phosphorus in the eutrophic lake water sample

\section{ACKNOWLEDGEMENTS}

This work was financially supported by the National Natural Science Foundation of China (No.21107001), the National Science and Technology support program (No. 2011BAJ03B04) and the Doctor Foundation of Anhui University of Architecture (2012).

\section{REFERENCES}

1. D.J. Conley, H.W. Paerl, R.W. Howarth, D.F. Boesch, S.P. Seitzinger, K.E. Havens, C. Lancelot and G.E. Likens, Science, 323, 1014 (2009).

2. D.W. Schindler, Science, 195, 260 (1977).

3. X. Jin, Q. Xu and C. Huang, Sci. China Ser. C: Life Sci., 48, 948 (2005).

4. T.D. French and E.L. Petticrew, Hydrobiologia, 575, 285 (2007).

5. Q. Zhou, C.E. Gibson and Y. Zhu, Chemosphere, 42, 221 (2001).

6. W. Xiong and J. Peng, Water Res., 42, 4869 (2008).

7. J.A. Rentz, I.P. Turner and J.L. Ullman, Water Res., 43, 2029 (2009).

8. S.K. Kang, K.H. Choo and K.H. Lim, Sep. Sci. Technol., 38, 3853 (2003).

9. D.R. Kioussis, F.W. Wheaton and P. Kofinas, Aquacult. Eng., 23, 315 (2000).

10. S. Nagamine, T. Ueda, I. Masuda, T. Mori, E. Sasaoka and I. Joko, Ind. Eng. Chem. Res., 42, 4748 (2003).

11. C. Barca, C. Gerente, D. Meyer, F. Chazarenc and Y. Andres, Water Res., 46, 2376 (2012).

12. J. Zhang, Z. Shen, Z. Mei, S. Li and W. Wang, J. Environ. Sci., 23, 199 (2011).

13. K.H. Goh, T.T. Lim and Z. Dong, Water Res., 42, 1343 (2008).

14. G. Zhang, H. Liu, R. Liu and J. Qu, J. Colloid Interf. Sci., 335, 168 (2009).

15. F. Haghseresht, S. Wang and D.D. Do, Appl. Clay Sci., 46, 369 (2009).

16. R.S.S. Wu, K.H. Lam, J.M.N. Lee and T.C. Lau, Chemosphere, 69, 289 (2007).

17. B.K. Biswas, K. Inoue, K.N. Ghimire, S. Ohta, H. Harada, K. Ohto and H. Kawakita, J. Colloid Interf. Sci., 312, 214 (2007). 